\title{
Determinants of an impaired quality of life five years after coronary artery bypass surgery
}

\author{
J Herlitz, I Wiklund, K Caidahl, B W Karlson, H Sjöland, M Hartford, M Haglid, \\ T Karlsson
}

\begin{abstract}
Objective-To identify determinants of an inferior quality of life (QoL) five years after coronary artery bypass grafting (CABG).

Setting-University hospital.

Participants-Patients from western Sweden who underwent CABG between 1988 and 1991.

Main outcome measures-Questionnaires for evaluating QoL before CABG and five years after operation. Three different instruments were used: the Nottingham health profile (NHP), the psychological general wellbeing index (PGWI), and the physical activity score (PAS).

Results-2121 patients underwent CABG, of whom 310 died during five years' follow up. Information on QoL after five years was available in 1431 survivors (79\%). There were three independent predictors for an inferior QoL with all three instruments: female sex, a history of diabetes mellitus, and a history of chronic obstructive pulmonary disease. Multivariate analysis showed that a poor preoperative QoL was a strong independent predictor for an impaired QoL five years after CABG. An impaired QoL was also predicted by previous disease.

Conclusions-Female sex, an impaired QoL before surgery, and other diseases such as diabetes mellitus are independent predictors for an impaired QoL after CABG in survivors five years after operation.
\end{abstract}

(Heart 1999;81:342-346)

Keywords: coronary artery bypass surgery; predictors; quality of life

Severe coronary artery disease can be successfully treated with coronary artery bypass grafting (CABG) with considerable relief of angina pectoris. ${ }^{1-3}$ Approximately three of four patients are free from ischaemic events for five years. ${ }^{4}$ However, increased survival is found only in selected subgroups with advanced coronary artery disease ${ }^{5}{ }^{6}$; this effect has not been established in elderly patients. ${ }^{17}$ The outcome of treatment in terms of quality of life (QoL) is of major importance in patients with severely symptomatic disease, particularly if a prognostic gain is not expected. QoL is defined as the individual's perception of symptoms, wellbeing, and physical and mental functional capacity. Previous major long term evaluations after CABG have focused on physical improvement, such as a reduction in angina pectoris, a reduction in nitrate medication, and an increase in exercise capacity. ${ }^{89}$ There is a lack of large long term studies of QoL using reliable, validated instruments. This study describes the impact of age, sex, disease history, and QoL before CABG on QoL five years after the operation.

\section{Patients and methods}

Patients from 15 hospitals in western Sweden underwent CABG at either Sahlgrenska University Hospital or the Scandinavian Heart Center, Göteborg, between June 1988 and June 1991. These hospitals are referral centres for CABG in western Sweden (1.6 million inhabitants). Patients received a questionnaire regarding QoL at coronary angiography before CABG and five years after the operation. Preoperative questionnaires were administered before coronary angiography to patients on waiting lists for elective angiography. Patients who underwent emergency coronary evaluation were given questionnaires in the ward before angiography.

Demographic data were collected by review of medical charts, interview, and physical examination of patients hospitalised for CABG by a physician from the research team. Functional classification was made according to the New York Heart Association (NYHA).

\section{QUALITY OF LIFE}

Patients completed three self administered questionnaires for assessment of QoL: the physical activity score (PAS), the Nottingham health profile (NHP), and the psychological general wellbeing index (PGWI) before and five years after surgery. These questionnaires have been carefully validated and tested for reliability. ${ }^{10-13}$ The PAS represents one dimension of an angina specific questionnaire, ${ }^{10}$ the angina pectoris $\mathrm{QoL}$ questionnaire, which contains six questions for self estimation of physical abilities and limitations. Each response is graded from one to six and the mean value for all six questions is calculated. The higher the total value, the greater the degree of disability.

The NHP is divided into two parts. Part one comprises 38 statements that convey limitations of activity or aspects of distress in six dimensions: physical mobility, pain, sleep, energy, social isolation, and emotional reactions. Patients indicate by a yes/no answer which problems they are experiencing when completing the questionnaire. A score ranging from nil to 100 can be calculated for each dimension; the higher the score, the greater the 
Table 1 Clinical characteristics of all patients

\begin{tabular}{|c|c|c|c|}
\hline & \multirow[b]{2}{*}{$\begin{array}{l}\text { All patients } \\
(n=2121)\end{array}$} & \multicolumn{2}{|l|}{ Responders } \\
\hline & & $\begin{array}{l}5 \text { years after } C A B G \\
(n=1431)\end{array}$ & $\begin{array}{l}\text { Preoperatively and } 5 \\
\text { years after } C A B G \\
(n=913)\end{array}$ \\
\hline Mean (SD) age (years) & $62.6(8.8)$ & $62.3(8.6)$ & $62.2(8.5)$ \\
\hline Female sex & $401(19)$ & $241(17)$ & $142(16)$ \\
\hline \multicolumn{4}{|l|}{ NYHA class } \\
\hline I & $54(3)$ & $34(2)$ & $14(2)$ \\
\hline II & $241(12)$ & $176(12)$ & $107(12)$ \\
\hline III & $1207(57)$ & $831(58)$ & $586(65)$ \\
\hline IV & $599(28)$ & $382(27)$ & $199(22)$ \\
\hline Previous MI (1)^ & $1296(61)$ & $839(59)$ & $513(56)$ \\
\hline Angina pectoris & 2067 (97) & $1397(98)$ & $899(98)$ \\
\hline Congestive heart failure (2) & $322(15)$ & $165(12)$ & $101(11)$ \\
\hline Hypertension (4) & $773(37)$ & $507(35)$ & $320(35)$ \\
\hline Diabetes mellitus (2) & $266(13)$ & $144(10)$ & $89(10)$ \\
\hline Renal dysfunction (5) & $585(28)$ & $335(23)$ & $198(22)$ \\
\hline Cerebrovascular disease (1) & $177(8)$ & $111(8)$ & $68(7)$ \\
\hline Claudication (3) & $260(12)$ & $140(10)$ & $91(10)$ \\
\hline COPD on medication & $77(4)$ & $47(3)$ & $26(3)$ \\
\hline Obesity & $263(12)$ & $165(12)$ & $114(12)$ \\
\hline Current smoker (13) & $275(13)$ & $154(11)$ & $99(11)$ \\
\hline Previous PTCA (1) & $110(5)$ & $71(5)$ & $33(4)$ \\
\hline Previous CABG & $121(6)$ & $73(5)$ & $40(4)$ \\
\hline Three vessel disease (70) & $1351(66)$ & $918(66)$ & $597(67)$ \\
\hline Ejection fraction $<40 \%(119)$ & $183(9)$ & $97(7)$ & $59(7)$ \\
\hline
\end{tabular}

Values are $\mathrm{n}(\%)$ unless otherwise stated.

${ }^{\star}$ Number of patients where information is missing.

COPD, Chronic obstructive pulmonary disease; PTCA, Percutaneous transluminal coronary angioplasty. treatment effects. ${ }^{18}$ The PGWI is suitable for evaluating the impact of symptoms on wellbeing and applicable for both healthy and patient populations. The purpose of this choice of questionnaires was to capture the range of outcomes, from symptomatic limitations of physical abilities due to angina pectoris to overall wellbeing and health related QoL. These questionnaires were chosen rather than other estimates, which have poorer ability to reflect subjective results after $\mathrm{CABG}$, such as the NYHA classification ${ }^{19}$ and return to work. ${ }^{20}$

\section{STATISTICAL METHODS}

The different QoL scores were dichotomised by defining an inferior QoL as worse than the median for the different instruments. Analyses were made in two steps. Firstly, univariate analysis of all baseline characteristics variables together with duration of angina, known valvular disease, height, weight, and body surface area was performed using Fisher's exact and the Mann-Whitney U tests (table 1) to examine associations with QoL. Secondly, variables associated with QoL with a $\mathrm{p}$ value of less than 0.05 were included in a stepwise logistic regression model to identify independent predictors of an inferior QoL. emotional problems.

The PGWI comprises 22 questions, dealing with six sections of wellbeing: anxiety, depressed mood, vitality, general health, self control, and wellbeing. ${ }^{13}$ The response format is graded from one to six - that is, total range 22-132, with the highest value corresponding to the best possible wellbeing.

\section{CHOICE OF QUESTIONNAIRES}

The symptomatic response to myocardial ischaemia in angina pectoris is chest discomfort, brought about by physical or mental stress, thereby limiting physical performance. However, angina pectoris affects various aspects of personality with increased anxiety and limitations of leisure activity, working capacity, and social and sexual function. ${ }^{14-16}$ The PAS represents one dimension of a disease specific questionnaire for estimating physical capacity, in patients with angina pectoris. ${ }^{10}$ The NHP and the PGWI are general questionnaires. The NHP is most useful for patients with chronic and pronounced symptoms ${ }^{17}$ and for detecting

\section{Results}

A total of 2121 patients underwent CABG in the study period, of whom $310(15 \%)$ died during five year follow up. Information on QoL after five years was available in 1431 survivors (79\%). Information on QoL before and five years after CABG was available in 913 patients ( $50 \%$ of survivors after five years).

The interval between answering the preoperative inquiry and the operation was significantly shorter for: patients older than 64 years than those 64 years or younger $(p=0.02)$; patients in functional class IV than those in functional classes I-III ( $p<0.0001)$; patients with a history of congestive heart failure compared with those without $(p=0.002)$; and patients with three vessel disease compared with those without $(\mathrm{p}<0.0001)$.

Table 1 shows the baseline characteristics of all patients who underwent CABG, patients for whom information on QoL was available five years after CABG, and patients for whom

Table 2 Independent predictors of an inferior quality of life five years after CABG: all survivors included

\begin{tabular}{|c|c|c|c|c|c|c|}
\hline & \multicolumn{2}{|c|}{ NHP total score $>5.8$ (median) } & \multicolumn{2}{|c|}{$\begin{array}{l}\text { PGWI total score }<107 \\
\text { (median) }\end{array}$} & \multicolumn{2}{|c|}{ PAS > 3.00 (median) } \\
\hline & $p$ value & OR $(95 \% C I)$ & p value & OR $(95 \% C I)$ & $p$ value & OR $(95 \% C I)$ \\
\hline Age & - & - & - & - & $<0.0001$ & $1.03(1.02$ to 1.05$)$ \\
\hline Female sex & $<0.0001$ & $2.1(1.6$ to 2.9$)$ & 0.004 & $1.5(1.1$ to 2.1$)$ & $<0.0001$ & $2.9(2.1$ to 4.1$)$ \\
\hline Functional class & - & - - n t & - & - & 0.0005 & $1.4(1.2$ to 1.7$)$ \\
\hline Previous MI & - & - & - & - & 0.03 & $1.3(1.0$ to 1.7$)$ \\
\hline Congestive heart failure & _- & _- & _- & - & 0.04 & $1.5(1.0$ to 2.3$)$ \\
\hline Hypertension & - & - & 0.006 & $1.4(1.1$ to 1.7$)$ & - & - \\
\hline Diabetes mellitus & 0.0002 & $2.1(1.4$ to 3.0$)$ & 0.003 & $1.8(1.2$ to 2.5$)$ & 0.0002 & $2.2(1.5$ to 3.4$)$ \\
\hline Cerebrovascular disease & - & - - ris & - & - & 0.04 & $1.6(1.0$ to 2.6$)$ \\
\hline Claudication & $<0.0001$ & $2.5(1.7$ to 3.8$)$ & - & - & $<0.0001$ & $3.2(2.1$ to 5.1$)$ \\
\hline COPD on medication & 0.003 & $2.8(1.4$ to 5.5$)$ & 0.01 & $2.4(1.2$ to 4.6$)$ & 0.02 & $2.4(1.2$ to 5.2$)$ \\
\hline Obesity & 0.002 & $1.8(1.2$ to 2.5$)$ & - & - & 0.002 & $1.8(1.3$ to 2.7$)$ \\
\hline Previous CABG & 0.002 & $2.3(1.3$ to 3.9$)$ & - & - & 0.0001 & $8.2(2.8$ to 24.0$)$ \\
\hline Three vessel disease & - & - & 0.04 & $0.8(0.6$ to 1.0$)$ & - & - \\
\hline
\end{tabular}

OR, Odds ratio; CI, Confidence intervals; MI, Myocardial infarction; COPD, Chronic obstructive pulmonary disease. 
Table 3 Independent predictors of an inferior quality of life five years after CABG in survivors in whom quality of life was assessed both before and five years after $C A B G$

\begin{tabular}{|c|c|c|c|c|c|c|}
\hline & \multicolumn{2}{|c|}{$\begin{array}{l}\text { NHP total score }>5.8 \\
\text { (median) }\end{array}$} & \multicolumn{2}{|c|}{$\begin{array}{l}\text { PGWI total score }<107 \\
\text { (median) }\end{array}$} & \multicolumn{2}{|c|}{$P A S>3.00$ (median) } \\
\hline & $p$ value & OR $(95 \% C I)$ & p value & OR $(95 \% C I)$ & $p$ value & OR $(95 \% C I)$ \\
\hline Preoperative inferior $\mathrm{QoL}^{\star}$ & $<0.0001$ & $3.8(2.8$ to 5.1$)$ & $<0.0001$ & $5.2(3.9$ to 7.0$)$ & 0.0002 & $1.8(1.3$ to 2.4$)$ \\
\hline Age & & & & & 0.004 & $1.03(1.01$ to 1.05$)$ \\
\hline Female sex & 0.003 & $1.9(1.2$ to 2.9$)$ & 0.05 & $1.5(1.0$ to 2.4$)$ & $<0.0001$ & $3.1(2.0$ to 4.6$)$ \\
\hline Functional class & & & & & 0.01 & $1.4(1.1$ to 1.8$)$ \\
\hline Hypertension & & & 0.004 & $1.6(1.1$ to 2.1$)$ & 0.02 & $1.5(1.1$ to 2.0$)$ \\
\hline Diabetes mellitus & 0.04 & $1.7(1.0$ to 2.9$)$ & & & 0.02 & $1.9(1.1$ to 3.1$)$ \\
\hline Renal dysfunction & & & 0.02 & $1.5(1.1$ to 2.2$)$ & & \\
\hline Cerebrovascular disease & 0.02 & $2.0(1.1$ to 3.6$)$ & 0.009 & $2.1(1.2$ to 3.8$)$ & 0.03 & $2.0(1.1$ to 3.5$)$ \\
\hline Claudication & 0.004 & $2.2(1.3$ to 3.6$)$ & & & $<0.0001$ & $3.3(1.9$ to 5.9$)$ \\
\hline COPD on medication & 0.03 & $3.2(1.2$ to 8.7$)$ & & & & \\
\hline Obesity & 0.04 & $1.6(1.0$ to 2.5$)$ & & & 0.002 & $2.1(1.3$ to 3.3$)$ \\
\hline Previous CABG & 0.02 & $2.5(1.1$ to 5.3$)$ & & & 0.003 & $3.3(1.5$ to 7.3$)$ \\
\hline
\end{tabular}

${ }^{\star}$ Defined as worse than median for the three different instruments, respectively.

OR, Odds ratio; CI, Confidence interval; COPD, Chronic obstructive pulmonary disease.

information was available before and five years after CABG.

PREDICTORS OF QOL FIVE YEARS AFTER CABG Survivors with available information at five years Table 2 shows independent predictors for an inferior QoL five years after CABG in all survivors. Three factors independently predicted an inferior QoL five years after CABG with all three instruments: female sex, patients with severe chronic obstructive pulmonary disease receiving medication, and a history of diabetes mellitus. Three factors predicted an impaired QoL with two of three instruments (NHP and PAS): obesity, intermittent claudication, and previous CABG. Five factors predicted an inferior QoL with PAS only: age, functional class, a history of cerebrovascular disease, congestive heart failure, and myocardial infarction. Two factors predicted an impaired QoL with PGWI only: absence of three vessel disease and a history of hypertension.

Survivors with information on QoL before and five years after $C A B G$

Table 3 shows independent predictors for an inferior QoL five years after CABG in survivors assessed before CABG and five years after the operation. As expected, preoperative scores indicating an impaired QoL were strong independent predictors for an impaired QoL five years after CABG with all three instruments. Some changes in results were seen compared with results in the first analysis. Thus, a history of cerebrovascular disease was an independent predictor for an impaired QoL with all three instruments, whereas a history of chronic obstructive pulmonary disease was a predictor only with the NHP. A history of diabetes was not a predictor for QoL with the
PGWI, whereas a history of congestive heart failure and myocardial infarction disappeared as independent predictors with the PAS.

\section{Simultaneous impact on subdimensions of the}

NHP

Generally, all factors in table 4 were strongly associated with somatic subdimensions (physical mobility and pain), whereas there was a less conspicuous association with psychosocial components (social isolation and emotional reactions).

Correlation between subscores before CABG and total scores five years after the operation

In terms of NHP there was a highly significant correlation between all six subdimensions before CABG and total scores five years after the operation ( $p<0.0001$ for all), with an $r$ value varying between 0.25 (social isolation) and 0.40 (sleep). In terms of PGWI there was also a highly significant correlation between all subdimensions before CABG and total scores five years after the operation $(p<0.0001$ for all), with an $r$ value varying between 0.35 (general health) and 0.47 (depressed).

\section{Discussion}

The main goals of CABG are relief of angina pectoris and prolongation of life expectancy. An improvement in health related QoL is another important end point. Health related QoL measures are used to evaluate the impact of disease and the effects of medical intervention. Such analyses are difficult because of the multidimensional complexity of QoL. Prospective studies may isolate factors that can identify patients at risk of a poor health related QoL postoperatively.

Table 4 Subdimensions of NHP (score above median) five years after CABG: simultaneous impact of independent predictors of NHP total score above median five years after $C A B G$

\begin{tabular}{|c|c|c|c|c|c|c|}
\hline & Physical mobility & Pain & Sleep & Energy & Social isolation & Emotional reactions \\
\hline Female sex & $2.9(2.1$ to 3.9$)$ & $2.5(1.9$ to 3.4$)$ & $1.4(1.0$ to 1.9$)$ & $1.6(1.2$ to 2.1$)$ & $1.7(1.2$ to 2.4$)$ & $1.0(0.7$ to 1.3$)$ \\
\hline Diabetes mellitus & $1.9(1.3$ to 2.7$)$ & $1.9(1.3$ to 2.7$)$ & $1.1(0.8$ to 1.7$)$ & $2.0(1.4$ to 2.8$)$ & $1.3(0.8$ to 2.0$)$ & $1.6(1.1$ to 2.3$)$ \\
\hline Claudication & $2.4(1.6$ to 3.5$)$ & $3.6(2.5$ to 5.3$)$ & $0.9(0.6$ to 1.3$)$ & $2.1(1.5$ to 3.1$)$ & $1.0(0.6$ to 1.6$)$ & $1.2(0.8$ to 1.7$)$ \\
\hline COPD on medication & $1.9(1.0$ to 3.6$)$ & $1.5(0.8$ to 2.9$)$ & $2.6(1.2$ to 6.0$)$ & $3.3(1.8$ to 6.1$)$ & $3.0(1.6$ to 5.5$)$ & $1.9(1.5$ to 5.3$)$ \\
\hline Obesity & $1.8(1.3$ to 2.6$)$ & $1.9(1.3$ to 2.7$)$ & $1.7(1.1$ to 2.5$)$ & $1.3(0.9$ to 1.9$)$ & $1.4(0.9$ to 2.1$)$ & $1.2(0.8$ to 1.7$)$ \\
\hline Previous CABG & 2.7 (1.6 to 4.6$)$ & $3.6(2.2$ to 6.2$)$ & $2.6(1.3$ to 4.9$)$ & $1.2(0.7$ to 2.0$)$ & $1.6(0.9$ to 2.8$)$ & $1.7(1.0$ to 2.8$)$ \\
\hline
\end{tabular}

Values are odds ratio and corresponding $95 \%$ confidence intervals.

COPD, Chronic obstructive pulmonary disease. 
Premorbid psychological status can predict some aspects of the recovery process after CABG ${ }^{21}$ Dispositional optimism as a personality resource can have an important role in the response to recovery from CABG. ${ }^{22}{ }^{23}$ Furthermore, preoperative denial was an adaptive mechanism in the early postoperative period, ${ }^{24}$ although it seemed to be maladaptive in the late postoperative period. ${ }^{23}$ Adjustment after CABG is probably a multidimension phenomenon explained by medical and psychosocial factors.

In the present study QoL five years after CABG was related to age, sex, and various preoperative factors, including a history of cardiovascular, peripheral vessel, renal, and pulmonary diseases, as well as functional status, ejection fraction, and the extent of coronary artery disease. Previous studies, particularly those using the $\mathrm{NHP},{ }^{25}{ }^{26}$ as well as the present study ${ }^{27}$ have shown a pronounced improvement in QoL after CABG. We assessed three overlapping aspects of QoL: physical activity, general quality of activity and relations, and psychological outcome. The study should be related to several earlier studies in which various aspects of QoL among patients with ischaemic heart disease affected outcome in a prolonged perspective. ${ }^{28-31}$

We found that female sex was an independent predictor for a poor QoL with all three instruments when preoperative QoL scores were analysed simultaneously. Moreover, previous studies have found that women with various manifestations of ischaemic heart disease have a worse QoL than men. ${ }^{32}{ }^{33}$ Similar observations have been reported in "healthy" individuals. ${ }^{34}$ The mechanisms responsible for these observations are not known.

In terms of patients having undergone CABG it is possible that rehabilitation regimens are less ambitious among women or that they receive less social support.

A history of diabetes mellitus was another predictor of a poor QoL. This observation is in agreement with previous results. ${ }^{35}$ In our two year follow up of this study population diabetic patients had an impaired QoL compared with that of patients without diabetes, although the improvement in QoL compared with that before surgery was similar in both groups. ${ }^{36}$ This finding is probably explained by increased morbidity and symptoms associated with organ dysfunction or variations in blood glucose concentrations.

A third independent predictor was a history of chronic obstructive pulmonary disease. The importance of this disease for wellbeing among patients with coronary artery disease is not well known. Nonetheless, chronic obstructive pulmonary disease was of less importance when preoperative QoL scores were analysed simultaneously for QoL five years after CABG.

A history of cerebrovascular disease was another important predictor for an impaired QoL five years after CABG, particularly when preoperative QoL scores were analysed. This information has not been described previously. These patients often suffer from functional limitations which can influence their QoL.
A history of hypertension was associated with an inferior QoL with PGWI and PAS when preoperative QoL scores were analysed. The mechanisms responsible for this observation are less clear as various organ complications associated with hypertension, such as renal disease, cerebrovascular disease, and congestive heart failure, were included in the multivariate model. However, the possibility that different complications appeared after the operation in patients with hypertension, thereby influencing QoL adversely, cannot be excluded. Furthermore, hypertensive patients were often treated with various medications, which might influence their QoL.

Intermittent claudication and obesity were also associated with an impaired QoL in some instruments. Both are well known to cause increased morbidity as well as various symptoms that can explain our observations.

\section{LIMITATIONS}

We were unable to administer reminders and this may have reduced the response rate. The results of patients who did not respond to the questionnaires cannot be accounted for, and such patients seemed to suffer from more severe coronary artery disease than the responders. Thus, we do not know if our results are applicable in a non-selected population undergoing CABG. Two major explanations for the low response rate before CABG were identified and estimated. Firstly, the fact that emergency surgery was performed precluded the possibility of making an assessment at short notice $(n=129)$. Secondly, of all patients operated on during the time period, 128 had already undergone coronary angiography before the start of the study and had not received a preoperative QoL questionnaire. These latter non-responders were unlikely to have systematically affected the outcome. These explanations account for $31 \%$ of preoperative nonresponders.

Predictors were limited to demographic and major medical variables in patients without psychosocial assessment at the time of operation.

\section{CONCLUSION}

Predictors for an impaired QoL after CABG among survivors five years after operation are female sex, an impaired QoL before CABG, a history of diabetes mellitus, chronic obstructive pulmonary disease, cerebrovascular disease, and previous CABG.

\footnotetext{
1 European Coronary Surgery Study Group. Long-term results of a prospective randomised study of coronary artery bypass surgery in stable angina pectoris. Lancet 1982;ii: $1173-80$.

2 CASS Principal Investigators and their Associates. Coronary artery surgery study (CASS): a randomized trial of coronary artery bypass surgery. Circulation 1983;68:951-60.

3 Hultgren HN, Peduzzi P, Detre K, et al and the Study Participants. The 5 year effect of bypass surgery on relief of angina and exercise performance. Circulation 1985; 72(suppl V):V-79-83.

4 Kirklin JW, Naftel DC, Blackstone EH, et al. Summary of a consensus concerning death and ischemic events after coronary artery bypass grafting. Circulation 1989;79(suppl I) :I-81-91.

5 Varnauskas E, and the European Coronary Surgery Study Group. Twelve year follow up of survival in the randomized European coronary surgery study. N Engl f Med 1988;319: 332-7.
} 
6 Califf RM, Harrell Jr FE, Lee KL, et al. The evolution of medical and surgical therapy for coronary artery disease: a 15 year perspective. $7 A M A$ 1989;261:2077-86.

7 CASS Principal Investigators and their Associates. Coronary artery surgery study (CASS): a randomized trial of coronary artery bypass surgery. Survival data. Circulation 1983;68:939-50.

8 Peduzzi P, Hultgren H, Thomsen J, et al. Ten year effect of medical and surgical therapy on quality of life: Veteran Administration cooperative study of coronary artery surgery. Am f Cardiol 1987;59:1017-23.

9 Rogers WJ, Coggin J, Gersh BJ, et al for the CASS investigators. Ten year follow up of quality of life in patients randomized to receive surgery. Circulation 1990;82:164758.

10 Wilson A, Wiklund I, Lahti T, et al. A summary index for the assessment of quality of life in angina pectoris. $\mathcal{F}$ Clin Epidemiol 1991;44:981-8.

11 Wiklund I, Romanus B, Hunt S. Self-assessed disability in patients with arthrosis of the hip joint. Reliability of the Swedish version of the Nottingham health profile. International Disability Studies 1988;10:159-63.

12 Hunt S, Wiklund I. Cross cultural variation in the weighting of health statements: a comparison of English and Swedish valuations. Health Policy 1987;8:227-35.

13 Dupuy $\mathrm{H}$. The psychological general well-being (PGWB) index. In: Wenger NK, Mattson ME, Furberg CD, Elinson $\mathrm{J}$, eds. Assessment of quality of life in clinical trials of cardiovascular therapies. New York: Le Jacq, 1984:170-83.

14 Mayou R. The patient with angina; symptoms and disability. Postgrad Med $\mathcal{f}$ 1973;49:250-4.

15 Dongier M. Psychosomatic aspects in myocardial infarction in comparison with angina pectoris. Psychother Psychosom 1974;23:123-31.

16 Smith TW, Follicle MJ, Korr KS. Anger, neuroticism, type A behaviour and the experience of angina. $\mathrm{Br} F \mathrm{Med}$ Psychol 1984;57:249-52.

17 Hunt S. Subjective health indicators and health promotion. Health Promotion 1986;3:1-12.

18 McCauley GA. Quality of life assessment before and after McCauley GA. Quality of life assessment before and after deficiency. Acta Paediatr Suppl 1989;365:70-2.

19 Goldman L, Hashimoto B, Cook F, et al. Comparative reproducibility and validity of systems for assessing cardiovascular functional class: advantages of a new specific activity scale. Circulation 1981;64:1227-34.

20 Walter PJ. Return to work after coronary artery bypass surgery. Eur Heart f 1988;9(suppl L):58-66.

21 Blumenthal JA, Mark DB. Quality of life and recovery after cardiac surgery [editorial comment]. Psychosom Med 1994; $56: 213-15$
22 Fitzgerald TE, Tennen $\mathrm{H}$, Affleck $\mathrm{G}$, et al. The relative importance of dispositional optimism and control appraisals in quality of life after cor

23 Duits AA, Boeke S, Taams MA, et al. Prediction of quality of life after coronary artery bypass graft surgery: a review and evaluation of multiple, recent studies. Psychosom Med 1997;59:257-68

24 Folks DG, Freeman AM, Sokol RS, et al. Denial: predictor of outcome following coronary bypass surgery. Int $\mathcal{f}$ Psychiatry Med 1988;18:57-66.

25 Caine N, Harrison SCW, Sharples LD, et al. Prospective study of quality of life before and after coronary artery bypass grafting. BMF 1991;302:511-16.

26 Pocock SI, Henderson RA, Seed P, et al for the RITA Trial Participants. Quality of life, employment status and anginal symptoms after coronary angioplasty or bypass surgery. Three year follow up in the randomized interventiongery. Three year follow un the randomized intervention treat-

27 Sjöland H, Caidahl K, Wiklund I, et al. Impact of coronary artery bypass grafting on various aspects of quality of life. artery bypass grafting on various aspects

28 Ladvig KH, Kieser M, König J, et al. Affective disorders and survival after acute myocardial infarction. Results from the post-infarction late potential study. Eur Heart F 1991;12: 59-64.

29 Freasure-Smith N, Lesperance F, Talajic M. Emotional disress following myocardial infarction. Impact on six month survival. FAMA 1993;270:1819-25.

30 Ladvig KH, Röll G, Breithardt G, et al. Post-infarction emotional distress and incomplete recovery six months after acute myocardial infarction. Lancet 1994;343:20-3.

31 Freasure-Smith N, Lesperance F, Taliajc M. Postmyocardial infarction depress

32 Wiklund I, Welin C. A comparison of different psychosocial questionnaires in patients wth myocardial infarction. Scand questionnaires in patients wth my
$\Im$ Rehabil Med 1992;24:195-202.

33 Wiklund I, Herlitz J, Johansson S, et al. Subjective symptoms and well being differ in women and men after myocardial and well being differ in women and men

34 Hunt SM, McEwen J, McKenna SP. Perceived health: age and sex norms in a community. F Epidemiol Community Health 1984;38:150-60

55 Keinanenkiukaanniemi S, Pajunpaa H, Ohinmaa A, et al. Health related quality of life in diabetic patients measured by the Nottingham health profile. Diabet Med 1996;13(4): 382-8.

36 Herlitz J, Sjöland H, Haglid M, et al. Impact of a history of diabetes mellitus on quality of life after coronary artery bypass grafting. Eur 7 Cardiothorac Surg 1997;12:853-6. 